\title{
Two-Echelon Inventory Optimization for Imperfect Production System under Quality Competition Environment
}

\author{
Xinfeng Lai, ${ }^{1}$ Zhixiang Chen, ${ }^{1}$ Bibhas C. Giri, ${ }^{2}$ and Chun-Hung Chiu ${ }^{1}$ \\ ${ }^{1}$ School of Business, Sun Yat-sen University, Guangzhou 510275, China \\ ${ }^{2}$ Department of Mathematics, Jadavpur University, Kolkata 700032, India \\ Correspondence should be addressed to Zhixiang Chen; mnsczx@mail.sysu.edu.cn
}

Received 7 August 2014; Revised 10 October 2014; Accepted 11 October 2014

Academic Editor: Tsan-Ming Choi

Copyright (c) 2015 Xinfeng Lai et al. This is an open access article distributed under the Creative Commons Attribution License, which permits unrestricted use, distribution, and reproduction in any medium, provided the original work is properly cited.

\begin{abstract}
This paper develops two integrated optimization models of two-echelon inventory for imperfect production system under quality competition environment, in which the vendor's production process is assumed to be imperfect, and JIT delivery policy is implemented to ship product from the vendor to the buyer. In the first model, product defect rate is fixed, and, in the second model, quality improvement investment is function of defect rate. The optimal policies of ordering quantity of buyer and shipment from vendor to buyer are obtained to minimize the expected annual total cost of vendor and buyer. Numerical examples are used to demonstrate the effectiveness and feasibility of the models. Sensitivity analysis is taken to analyze the impact of demand, production rate, and defect rate on the solution. Implications are highlighted in that both the vendor and the buyer can benefit from the vendor's investing in quality improvement.
\end{abstract}

\section{Introduction}

Nowadays, quality is a very important competition weapon; manufacturing firms must produce perfect goods in a perfect production system to compete with rivals. However, imperfect production condition exists in reality, such as imperfect supply system, imperfect machine maintenance, imperfect process, and imperfect workforce. Facing this imperfect production condition, firms on one hand need to carry out continuous improvement strategy to improve the production system and on the other hand need to make appropriate operation decision considering the imperfect production condition. This paper focuses on how to make the appropriate inventory decision for a two-echelon supply chain consisting of single vendor and single buyer, currently considering imperfect production condition of machine inspection and quality improvement strategy.

The traditional economic production quantity (EPQ) model assumes that the production process is perfect and no imperfect items are produced. However, in practice, the production facility is not failure-free and product quality is also not always perfect. In practice, the imperfect items would be rejected, repaired, and reworked, and thus extra costs are incurred. Several researches have been undertaken to study inventory models with imperfect quality. Rosenblatt and Lee [1] studied an imperfect production process with optimizing production cycle time. Their result shows that the optimal production cycle is shorter than that of the classical economic manufacturing quantity model. Salameh and Jaber [2] developed a classical economic order quantity model for items with imperfect quality. Wee et al. [3] extended Salameh and Jaber's [2] model with the permission of shortage. CárdenasBarrón [4] studied an economic production quantity model with rework process at a single-stage manufacturing system with planned backorders. Chung [5] revisited the work of Cárdenas-Barrón [4] and developed the sufficient and necessary condition for the existence of the solution.

Chang and Ho [6] revised Wee et al.s [3] model and derived the exact solution to the optimal inventory model for items with imperfect quality and shortage backordering. J.-T. Hsu and L.-F. Hsu [7] developed an economic order quantity (EOQ) model with imperfect quality items, 
inspection errors, shortage backordering, and sales returns. The model presented a closed form solution to the optimal order size, the maximum shortage level, and the optimal order/reorder point. Khouja and Mehrez [8] developed an economic production lot size model with imperfect quality and variable production rate. Sana [9] extended Khouja and Mehrez's [8] model and investigated an economic production lot size model in an imperfect production system, in which the production facility may shift from an "in-control" state to an "out-of-control" state at any random time.

Besides the EPQ and EOQ models with imperfect items and processes, in the past, vendor-buyer integrated inventory management related to imperfect quality also has been studied. Huang [10] presented an integrated vendor-buyer inventory model for imperfect quality items. Goyal et al. [11] developed a simple approach for determining an optimal integrated vendor-buyer inventory policy for an item with imperfect quality. Huang [12] developed a model to determine an optimal integrated vendor-buyer inventory policy for flawed items in a JIT manufacturing environment. Ouyang et al. [13] proposed three methods to determine defect rate (crisp, fuzzy, and mixture of statistic and fuzzy) in an integrated vendor-buyer inventory model involving defective items. J.-T. Hsu and L.-F. Hsu [14, 15] developed a mathematical model to determine an integrated vendorbuyer inventory policy, where the vendor's production process is imperfect and produces a certain number of defective items.

In practice, product quality is usually related to the state of the production process. When the production process is in control state, the items would be in high quality level (perfect). As time goes on, the process state may deteriorate and imperfect items are produced. In recent years, some authors have studied production-inventory models with process inspection. Marek [16] considered the problem of optimization of a quality inspection process and presented a solution of optimal inspection operations in a production process. However, the inspection process is not relevant to the imperfect quality. Lee and Rosenblatt [17] developed an EMQ (economic manufacturing quantity) model of joint control of production cycles or manufacturing quantities and maintenance by inspection. Giri and Dohi [18] considered inspection process for imperfect production process where the process state shifts randomly. During each production run, the process is monitored through inspections to assess its state. J. T. Hsu and L. F. Hsu [19] developed an integrated vendor-buyer production-inventory model for items with imperfect quality and inspection errors. The production process is imperfect and produces a certain number of defective items. At the same time, the buyer's quality screening process is not perfect either. This model derives the optimal solution to integrated total annual cost. Khan et al. [20] adopted an approach similar to Salameh and Jaber [2] to study an optimal production/order quantity with imperfect processes. J.-T. Hsu and L.-F. Hsu [21] pointed out a contradiction between Lee's [22] model and their assumption and developed a modified model. Yoo et al. [23] studied the imperfect production and inspection processes in a stable production and inventory system. They developed the imperfect quality inventory models for various inspection options. Avinadav and Perlman [24] considered a batch production process that can be either stable or unstable, in which inspection is performed offline after production of the batch is completed. Chung [25] developed an integrated two-stage production-inventory deteriorating model for replenishment policy and inspection plan. Khan et al. [26] developed an integrated vendor-buyer inventory model accounting for quality inspection errors at the buyer's end.

Additionally, some researchers have studied the inventory models incorporating the issue of investment in product quality improvement. Porteus [27] developed a model that captured a relationship between quality and lot size and discussed three options for investing in quality improvements. Hong [28] incorporated joint investment in setup reduction and process quality improvement into a production system with imperfect production processes, where he assumed that setup reduction and process quality are functions of capital expenditure. Lee [22] developed a cost/benefit model for supporting investment strategies about inventory and preventive maintenance in an imperfect production system. Hou [29] considered an EPQ model with imperfect production processes, in which the setup cost and process quality are functions of capital expenditure. They studied the effects of an imperfect production process on the optimal production cycle time after capital investment strategies and process quality improvements are adopted. Yoo et al. [30] examined an imperfect production and inspection system and analyzed the solutions for different investment strategies.

The purpose of this paper is to extend Huang's [12]. First, in this paper, we consider process inspections during production run, while Huang's model does not consider this; second, we extend Huang's model to another model for consider quality improvement investment. The main contributions of this paper lie in the fact that we extended the previous study on the vendor-buyer inventory model by considering the imperfect production condition and quality improvement investment and provided implications for practitioners in inventory decision.

The rest of the paper is organized as follows. In Section 2, notations and assumptions are first presented and then the proposed model of single-vendor single-buyer inventory for defect items is formulated; again, the proposed model is extended to consider capital investment in quality improvement. In Section 3, numerical examples and sensitivity analysis are given. Finally, conclusions and future research directions are given in Section 4.

\section{Formulation of the Model}

In this paper, we assume a supply chain comprised of a vendor (manufacturer) and buyer (retailer); the vendor produces product and delivers it to a buyer (retailer). An equal lot size policy is adopted. The vendor's production process is assumed to be imperfect and a fraction of defective items are produced during a production run. The machine always starts in an in-control state but may shift to the out-of-control state at any random time and produce some defective items. To reduce the number of defective items, the vendor performs 
periodic machine inspections during a production run and the $100 \%$ quality screening for defective items is conducted by the buyer. Further, we extend the model to consider capital investment in quality improvement by vendor. The capital investment is assumed to follow the Porteus [27] logarithmic investment function.

The questions addressed in this paper are as follows: what is the optimal inventory policy for the integrated singlevendor single-buyer system with imperfect items? And what is the optimal investment strategy for quality improvement? In order to answer these questions, in this paper, we construct two integrated production-inventory models. In the first model, defect rate is assumed to be a fixed value, and, in the second model, we extend the first model to consider the vendor's investment in quality improvement, and investment is function of defect rate, and then the vendor's cost will include capital investment.

2.1. Assumptions and Notations. The following assumptions are used throughout this paper for formulation of the problem.

(1) The supply chain system consists of a single vendor and a single buyer for trading a single product.

(2) The vendor's production rate is constant and greater than the buyer's demand rate.

(3) The vendor's production system is imperfect. It always starts in an in-control state but may shift to the outof-control state at any random time and produce some defective items.

(4) The vendor process performs periodic inspections during a production run. At each inspection if the machine is found in out-of-control state, then restoration is done. Otherwise, preventive maintenance is performed to enhance system reliability.

(5) The production process restoration cost is proportional to the detection delay time.

(6) After process restoration, the machine becomes as good as new.

(7) Process inspection and restoration times are negligible.

(8) The buyer performs a $100 \%$ quality screening for delivered products. The screening rate is much higher than the customer demand rate.

(9) In the second model, the vendor conducts a capital investment to improve product quality; the investment cost is considered part of the total cost.

\section{Notations}

\section{Parameters}

$P$ : Production rate of the vendor

$D$ : Annual demand of the buyer

$S_{v}:$ Vendor's setup cost per production run
$S_{b}$ : Buyer's ordering cost per order

$h_{v}$ : Vendor's unit holding cost

$h_{b}$ : Buyer's unit holding cost

$\mathrm{C}_{0}$ : Process inspection cost

$C_{1}$ : Preventive maintenance cost

$r$ : Machine restoration cost per unit detection delay time

$T_{i}$ : $i$ th process inspection time, $i=1,2, \ldots, m ;\left(T_{1}, T_{2}\right.$, $\left.\ldots, T_{m}\right)$ is the inspection time sequence

$T$ : Time interval between two successive deliveries to the buyer

$T_{m}$ : Vendor's production time in a cycle

$N_{i}$ : Number of defective items produced in the time interval $\left[T_{i-1}, T_{i}\right], i=1,2, \ldots, m ; T_{0}=0$

$R_{i}$ : Process restoration cost in the time interval $\left[T_{i-1}, T_{i}\right], i=1,2, \ldots, m$

$\tau$ : Elapsed time of a shift from the "in-control" state to the "out-of-control" state in vendor production process

$f(\cdot)$ : Probability density function of the time to process shift from in-control state to out-of-control state

$F(\cdot)$ : Probability distribution function of the time to process shift from in-control state to out-of-control state

$d$ : Unit screening cost for defective items

$k$ : Unit penalty cost for defective items

$x$ : Quality screening rate for defective items

A: Buyer's transportation cost per shipment

$\alpha_{0}$ : The original percentage of defective items before investment

$\alpha$ : Percentage of defective items produced when process is in "out-of-control" state

$\eta$ : Fractional opportunity cost

$\delta$ : The percentage of decrease in defective items per dollar increase in quality improvement investment.

\section{Decision Variables}

$t_{i}$ : $i$ th inspection interval for process in the vendor; that is, $t_{i}=T_{i}-T_{i-1}$ for all $i=1,2, \ldots, m ; T_{0}=0$

$n$ : Number of shipments per lot from the vendor to the buyer, a positive integer

$m$ : Number of process inspections during each production run

Q: Shipment size from the vendor to the buyer. 


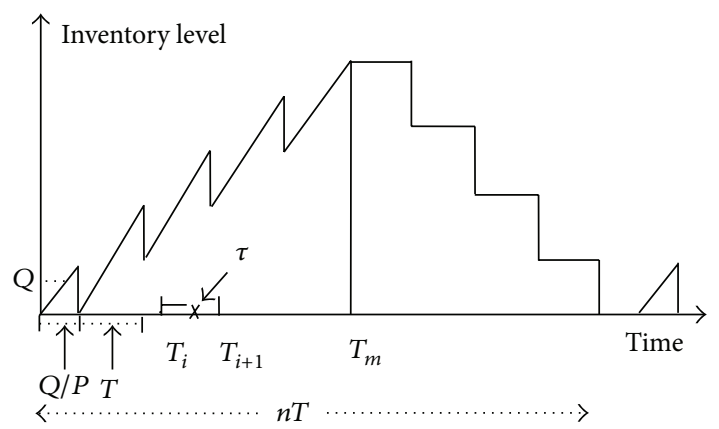

FIGURE 1: Production inventory of vendor.

2.2. Mathematical Model. The vendor's production-inventory pattern is shown in Figure 1. Since the delivery of product follows a JIT small lot size delivery policy, each time one delivery quantity $Q$ is shipped to buyer, the production rate is $P$, and the number of deliveries during one production cycle is $n$, the production cycle time is $T$, and we suppose that $m$ times process inspections are carried out during a production run. Therefore, process inspections are performed at times $T_{1}, T_{2}, \ldots, T_{m}$. At each process inspection if the machine is found in out-of-control state, then restoration is done. Otherwise, preventive maintenance is performed to enhance system reliability.

Each time, a lot of size $Q$ is delivered from the vendor to the buyer, and it is assumed that each lot contains a percentage of defective items, $\alpha$. After the items are delivered to the buyer, the buyer performs a $100 \%$ quality screening to identify the defective items with a screening rate of $x$ and discards the defective items at the end of screening process. A typical configuration of the buyer's inventory level fluctuation is shown in Figure 2, where $T$ is the order cycle length, $\alpha Q$ is the number of defective items withdrawn from inventory, and $t$ is the total screening time of $Q$ units.

\subsubsection{The Integrated Decision of the Vendor and the Buyer}

(1) The Vendor's Cost per Unit Time. Figure 3 shows the accumulation of vendor's inventory in a cycle. The shaded rectangles are the total inventory delivered to the buyer. Following the method in Huang [12], the vendor's holding inventory area equals the sum of the areas of triangle and rectangle minus shaded area.

Thus, the vendor's inventory holding cost per unit time can be obtained as

\section{Holding cost}

$$
\begin{aligned}
=h_{v}\left\{n Q\left(\frac{Q}{P}+(n-1) T\right)-\frac{n Q(n Q / P)}{2}\right. \\
-T[Q+2 Q+\cdots+(n-1) Q]\} \\
=\frac{h_{v} n Q^{2}}{2}\left\{\frac{2-n}{P}+\frac{(n-1)(1-\alpha)}{D}\right\} .
\end{aligned}
$$

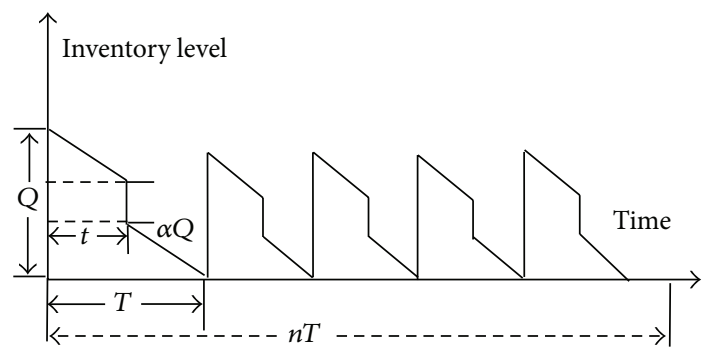

FIGURE 2: Inventory level variation of buyer in a cycle.

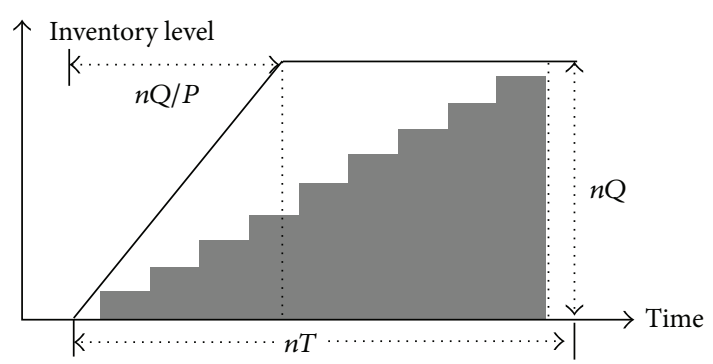

FIGURE 3: Inventory accumulation of vendor in a cycle.

We define $\tau$ as the elapsed time of a shift from the "incontrol" state to "out-of-control" state, and $\tau$ is a random variable. Inspections are undertaken at time $T_{i}$ and either restoration or preventive maintenance is carried out at each inspection; therefore, $\left(t_{i}-\tau\right)$ is the detection delay time in the time interval $\left[T_{i-1}, T_{i}\right], i=1,2, \ldots, m$, and during this delay period some defective items are produced. The vendor's restoration cost $R_{i}$ in $\left[T_{i-1}, T_{i}\right]$ is given by

$$
R_{i}= \begin{cases}0, & \text { if } \tau \geq t_{i}, \\ r\left(t_{i}-\tau\right), & \text { if } \tau<t_{i}\end{cases}
$$

Thus, the vendor's expectation restoration cost in the time interval $\left[T_{i-1}, T_{i}\right]$ is $E\left[R_{i}\right]=\int_{0}^{t_{i}} r\left(t_{i}-\tau\right) f(\tau) d \tau$, and the vendor's expected total restoration cost is

$$
\sum_{i=1}^{m} E\left[R_{i}\right]=\sum_{i=1}^{m} \int_{0}^{t_{i}} r\left(t_{i}-\tau\right) f(\tau) d \tau .
$$

The number of defective items $\left(N_{i}\right)$ produced in the time interval $\left[T_{i-1}, T_{i}\right]$ is

$$
N_{i} \approx \begin{cases}0, & \text { if } \tau \geq t_{i} \\ \alpha P\left(t_{i}-\tau\right), & \text { if } \tau<t_{i}\end{cases}
$$

and the expected number of defective items produced in the time interval $\left[T_{i-1}, T_{i}\right]$ is $E\left(N_{i}\right)=\int_{0}^{t_{i}} \alpha P\left(t_{i}-\tau\right) f(\tau) d \tau$. The vendor's defective items production cost or penalty cost is $k \sum_{i=1}^{m} E\left(N_{i}\right)$, total inspection cost is $m C_{0}$, and preventive maintenance cost is $\sum_{i=1}^{m} C_{1} \bar{F}\left(t_{i}\right)$.

The vendor's total cost in a cycle is the sum of the setup cost, inspection cost, holding cost, defective items penalty 
cost, restoration cost, and preventive maintenance cost. We can write the total cost of the vendor as

$$
\begin{aligned}
& \mathrm{ETC}_{V}\left(t_{i}, n, Q\right) \\
& =\frac{1}{n T}\left\{S_{v}+m C_{0}+\frac{h_{v} n Q^{2}}{2}\right. \\
& \\
& \times\left(\frac{2-n}{P}+\frac{(n-1)(1-\alpha)}{D}\right)+k \sum_{i=1}^{m} E\left(N_{i}\right) \\
& \left.+\sum_{i=1}^{m} \int_{0}^{t_{i}} r\left(t_{i}-\tau\right) f(\tau) d \tau+\sum_{i=1}^{m} C_{1} \bar{F}\left(t_{i}\right)\right\} .
\end{aligned}
$$

(2) The Buyer's Cost per Unit Time. The buyer's total cost in a cycle is the sum of ordering cost, holding cost, transportation cost, and quality screening cost. The buyer's holding cost per unit time is

$$
\frac{h_{b}}{T}\left(\frac{Q(1-\alpha) T}{2}+\frac{\alpha Q^{2}}{x}\right)=h_{b}\left[\frac{Q(1-\alpha)}{2}+\frac{\alpha D Q}{x(1-\alpha)}\right] \text {. }
$$

The buyer's ordering cost per unit time $=S_{b} / n T=$ $S_{b} D / n(1-\alpha) Q$. The buyer's transportation cost per unit time is $A / T=A D /(1-\alpha) Q$. The buyer's quality screening cost per unit time is $d Q / T=d D /(1-\alpha)$. Thus, we can write the expected total cost of the buyer per unit time as

$$
\begin{aligned}
\operatorname{ETC}_{B}(n, Q)= & h_{b}\left[\frac{Q(1-\alpha)}{2}+\frac{\alpha D Q}{x(1-\alpha)}\right]+\frac{S_{b} D}{n(1-\alpha) Q} \\
& +\frac{A D}{(1-\alpha) Q}+\frac{d D}{(1-\alpha)} .
\end{aligned}
$$

(3) The Integrated Vendor-Buyer Inventory Model. Using (5) and (7), the expected total cost of the integrated inventory system can be obtained as

$$
\begin{aligned}
& \operatorname{ETC}\left(t_{i}, n, Q\right) \\
& =\operatorname{ETC}_{V}\left(t_{i}, n, Q\right)+\operatorname{ETC}_{B}(n, Q) \\
& =\frac{1}{n T}\left\{S_{v}+m C_{0}+\frac{h_{v} n Q^{2}}{2}\right. \\
& \times\left(\frac{2-n}{P}+\frac{(n-1)(1-\alpha)}{D}\right) \\
& +k \sum_{i=1}^{m} \int_{0}^{t_{i}} \alpha P\left(t_{i}-\tau\right) f(\tau) d \tau \\
& \quad+\sum_{i=1}^{m} \int_{0}^{t_{i}} r\left(t_{i}-\tau\right) f(\tau) d \tau \\
& \left.\quad+\sum_{i=1}^{m} C_{1} \bar{F}\left(t_{i}\right)\right\}+h_{b}\left[\frac{Q(1-\alpha)}{2}+\frac{\alpha D Q}{x(1-\alpha)}\right] \\
& +\frac{S_{b} D}{n(1-\alpha) Q}+\frac{A D}{(1-\alpha) Q}+\frac{d D}{(1-\alpha)} .
\end{aligned}
$$

Putting $T=(1-\alpha) Q / D$ in $(8)$, we obtain

$$
\begin{aligned}
& \operatorname{ETC}\left(t_{i}, n, Q\right) \\
& \begin{aligned}
& n(1-\alpha) Q \\
& \times\left\{S_{v}+m C_{0}+\frac{h_{v} n Q^{2}}{2}\right. \\
& \times\left(\frac{2-n}{P}+\frac{(n-1)(1-\alpha)}{D}\right) \\
&+k \sum_{i=1}^{m} \int_{0}^{t_{i}} \alpha P\left(t_{i}-\tau\right) f(\tau) d \tau \\
&\left.+\sum_{i=1}^{m} \int_{0}^{t_{i}} r\left(t_{i}-\tau\right) f(\tau) d \tau+\sum_{i=1}^{m} C_{1} \bar{F}\left(t_{i}\right)\right\} \\
&+ h_{b}\left[\frac{Q(1-\alpha)}{2}+\frac{\alpha D Q}{x(1-\alpha)}\right] \\
&+ \frac{S_{b} D}{n(1-\alpha) Q}+\frac{A D}{(1-\alpha) Q}+\frac{d D}{(1-\alpha)} .
\end{aligned}
\end{aligned}
$$

In the above equation, although the decision variable $n$ is an integer, we can slack it as continuous variable, and then we take the derivate of the above equation to obtain the solution which is shown in the following steps.

For convenience of formulation, we define

$$
\begin{aligned}
G(\cdot)= & k \sum_{i=1}^{m} \int_{0}^{t_{i}} \alpha P\left(t_{i}-\tau\right) f(\tau) d \tau \\
& +\sum_{i=1}^{m} \int_{0}^{t_{i}} r\left(t_{i}-\tau\right) f(\tau) d \tau+\sum_{i=1}^{m} C_{1} \bar{F}\left(t_{i}\right),
\end{aligned}
$$

and then, taking the first derivative of ETC with respect to $n$, we have

$$
\begin{aligned}
\frac{\partial \mathrm{ETC}}{\partial n}= & -\frac{D}{n^{2}(1-\alpha) Q}\left\{S_{v}+m C_{0}+S_{b}+G(\cdot)\right\} \\
& +\frac{D}{(1-\alpha)} \frac{h_{v} Q}{2}\left(\frac{1}{D}-\frac{1}{P}\right) .
\end{aligned}
$$

The total cost function ETC is convex in $n$, since it is easy to see that

$$
\frac{\partial^{2} \mathrm{ETC}}{\partial n^{2}}=\frac{2 D}{n^{3}(1-\alpha) Q}\left\{S_{v}+m C_{0}+S_{b}+G(\cdot)\right\}>0
$$

$\forall n \geq 1$.

Taking the first derivative of ETC with respect to $Q$, we have

$$
\begin{aligned}
\frac{\partial \mathrm{ETC}}{\partial Q}= & -\frac{D}{n(1-\alpha) Q^{2}}\left\{S_{v}+m C_{0}+S_{b}+A n+G(\cdot)\right\} \\
& +\frac{(2-n) D h_{v}}{(1-\alpha) P}+\frac{(n-1) h_{v}}{2}+h_{b}\left(\frac{1}{2}+\frac{\alpha D}{x(1-\alpha)}\right) .
\end{aligned}
$$


For fixed values of $n$ and $t_{i}$, ETC can also be shown to be convex in $Q$, since

$$
\frac{\partial^{2} \mathrm{ETC}}{\partial Q^{2}}=\frac{2 D}{n(1-\alpha) Q^{3}}\left\{S_{v}+m C_{0}+S_{b}+A n+G(\cdot)\right\}>0 .
$$
have

Taking the first derivative of ETC with respect to $t_{i}$, we

$$
\begin{aligned}
\frac{\partial \mathrm{ETC}}{\partial t_{i}} & =\frac{D}{n(1-\alpha) \mathrm{Q}} \frac{\partial G(\cdot)}{\partial t_{i}} \\
\frac{\partial G(\cdot)}{\partial t_{i}} & =k \alpha P \int_{0}^{t_{i}} f(\tau) d \tau+r \int_{0}^{t_{i}} f(\tau) d \tau-C_{1} f\left(t_{i}\right) .
\end{aligned}
$$

Therefore,

$$
\begin{gathered}
\frac{\partial \mathrm{ETC}}{\partial t_{i}}=\frac{D}{n(1-\alpha) Q}\left\{(k \alpha P+r) \int_{0}^{t_{i}} f(\tau) d \tau-C_{1} f\left(t_{i}\right)\right\} \\
\frac{\partial^{2} \mathrm{ETC}}{\partial t_{i}^{2}}=\frac{D}{n(1-\alpha) Q}\left\{(k \alpha P+r) f\left(t_{i}\right)-C_{1} f^{\prime}\left(t_{i}\right)\right\} \\
i=1, \ldots, m, \\
\frac{\partial^{2} \mathrm{ETC}}{\partial n \partial Q}=\frac{D}{n^{2}(1-\alpha) Q^{2}}\left\{S_{v}+m C_{0}+S_{b}\right. \\
+k \sum_{i=1}^{m} \int_{0}^{t_{i}} \alpha P\left(t_{i}-\tau\right) f(\tau) d \tau \\
+\frac{h_{v}}{2}\left(1-\frac{D}{P(1-\alpha)}\right)>0
\end{gathered}
$$$$
\frac{\partial^{2} \mathrm{ETC}}{\partial n^{2}} \cdot \frac{\partial^{2} \mathrm{ETC}}{\partial Q^{2}}-\left(\frac{\partial^{2} \mathrm{ETC}}{\partial n \partial Q}\right)^{2}
$$$$
=\left(4 D^{2}\left(S_{v}+m C_{0}+S_{b}+G(\cdot)\right)\right.
$$$$
\left.\times\left(S_{v}+m C_{0}+S_{b}+G(\cdot)+A n\right)\right)\left(n^{4}(1-\alpha)^{2} Q^{4}\right)^{-1}
$$$$
-\frac{D^{2}}{n^{4}(1-\alpha)^{2} Q^{4}}
$$$$
\times\left[S_{v}+m C_{0}+S_{b}+G(\cdot)+\frac{h_{v}}{2}\left(1-\frac{D}{P(1-\alpha)}\right)\right]^{2}
$$$$
=\frac{D^{2}}{n^{4}(1-\alpha)^{2} Q^{4}}\left\{4\left(S_{v}+m C_{0}+S_{b}+G(\cdot)\right)\right.
$$$$
\times\left(S_{v}+m C_{0}+S_{b}+G(\cdot)+A n\right)
$$$$
-\left[S_{v}+m C_{0}+S_{b}+G(\cdot)\right.
$$$$
\left.\left.+\frac{h_{v}}{2}\left(1-\frac{D}{P(1-\alpha)}\right)\right]^{2}\right\}
$$

$$
\begin{aligned}
> & \frac{D^{2}}{n^{4}(1-\alpha)^{2} Q^{4}} \\
& \times\left\{\left[2\left(S_{v}+m C_{0}+S_{b}+G(\cdot)\right)\right]^{2}\right. \\
& \quad \frac{\left.-\left[S_{v}+m C_{0}+S_{b}+G(\cdot)+\frac{h_{v}}{2}\left(1-\frac{D}{P(1-\alpha)}\right)\right]^{2}\right\}}{n^{4}(1-\alpha)^{2} Q^{4}} \\
& \times\left[3\left(S_{v}+m C_{0}+S_{b}+G(\cdot)\right)+\frac{h_{v}}{2}\left(1-\frac{D}{P(1-\alpha)}\right)\right] \\
& \cdot\left[S_{v}+m C_{0}+S_{b}+G(\cdot)-\frac{h_{v}}{2}\left(1-\frac{D}{P(1-\alpha)}\right)\right]>0 .
\end{aligned}
$$

Note that if $(k \alpha P+r) f\left(t_{i}\right)-C_{1} f^{\prime}\left(t_{i}\right)>0$, then we have $\partial^{2} \mathrm{ETC} / \partial t_{i}^{2}>0, \partial^{2} \mathrm{ETC} / \partial n^{2}>0, \partial^{2} \mathrm{ETC} / \partial Q^{2}>0$, and $\left(\partial^{2} \mathrm{ETC} / \partial n^{2}\right) \cdot\left(\partial^{2} \mathrm{ETC} / \partial Q^{2}\right)-\left(\partial^{2} \mathrm{ETC} / \partial n \partial Q\right)^{2}>0$ implying that, for any given value of $n$, the total cost function is convex. Therefore, there exists a unique value of $Q$ that minimizes (8).

The optimal lot size is given by

$$
Q^{*}(n)=\sqrt{\frac{D\left(S_{v}+m C_{0}+S_{b}+A n+G(\cdot)\right)}{n(1-\alpha) M(\cdot)}},
$$

where

$$
M(\cdot)=\frac{(2-n) D h_{v}}{(1-\alpha) P}+\frac{(n-1) h_{v}}{2}+h_{b}\left(\frac{1}{2}+\frac{\alpha D}{x(1-\alpha)}\right) .
$$

Note that the condition $(k \alpha P+r) f\left(t_{i}\right)-C_{1} f^{\prime}\left(t_{i}\right)>0$ is clearly satisfied for uniform distribution, since $(k \alpha P+r)>0$, $f\left(t_{i}\right)>0, f^{\prime}\left(t_{i}\right)=0$.

From the optimality condition $\partial \mathrm{ETC} / \partial t_{i}=0$, we can get

$$
(k \alpha P+r) \int_{0}^{t_{i}} f(\tau) d \tau-C_{1} f\left(t_{i}\right)=0 .
$$

Using (19), we find out the optimal value of $t_{i}^{*}$ as follows. Equation (19) can be extended as follows:

$$
\begin{gathered}
(k \alpha P+r) \int_{0}^{t_{1}} f(\tau) d \tau-C_{1} f\left(t_{1}\right)=0, \\
(k \alpha P+r) \int_{0}^{t_{2}} f(\tau) d \tau-C_{1} f\left(t_{2}\right)=0 \\
\vdots \\
(k \alpha P+r) \int_{0}^{t_{n}} f(\tau) d \tau-C_{1} f\left(t_{n}\right)=0 .
\end{gathered}
$$

If $f(x)$ follows uniform probability distribution, that is,

$$
f(x)= \begin{cases}\frac{1}{b}, & \text { if } 0<x<b \\ 0, & \text { otherwise. }\end{cases}
$$


From (19) we can obtain

$$
t_{1}^{*}=t_{2}^{*}=\cdots=t_{n}^{*}=\frac{C_{1}}{k \alpha P+r} .
$$

This result shows that the optimal machine inspection interval of each time is a fixed value, which is dependent on the parameters of the machine maintenance and inspection. In other words, when the inspection interval of each time is constant, the total cost is minimum. Since production run is $n Q / P$, we can obtain $m=n Q / P t_{i}^{*}$.

In order to determine the optimal $n$ that minimizes $\operatorname{ETC}(n, Q)$, the following procedure can be implemented.

Algorithm 1. Consider the following.

Step 1. For a range of values of $n$, determine the corresponding $Q^{*}(n)$ using (17) and compute $\operatorname{ETC}\left(n, Q^{*}(n)\right)$ by substituting $Q^{*}(n)$ into (9).

Step 2. Derive the optimal value of $n$, denoted by $n^{*}$, such that $\operatorname{ETC}\left(n, Q^{*}(n)\right) \leq \operatorname{ETC}\left(n-1, Q^{*}(n-1)\right)$ and $\operatorname{ETC}\left(n, Q^{*}(n)\right) \leq$ $\operatorname{ETC}\left(n+1, Q^{*}(n+1)\right)$.

Once we derive out $n^{*}$, the optimal size of a production batch can be obtained by $n^{*} Q^{*}(n)$.

\subsubsection{The Integrated Model with Capital Investment for Quality} Improvement. We now suppose that the vendor invests some capital in order to reduce the number of defective items produced. We assume a logarithmic investment function as $I(\alpha)=(\eta / \delta) \ln \left(\alpha_{0} / \alpha\right)$ [27], where $\alpha_{0}$ is the defect rate before quality improvement, $\eta$ means the fractional opportunity cost, and $\delta$ means the percentage of decrease in defective items per dollar increase in investment.

In this situation, the new expected total cost of the integrated model equals the total cost of the system without investment (i.e., the first model) plus the capital investment by the vendor.

Then, the expected total cost of the integrated model can be obtained as

$$
\begin{aligned}
& \mathrm{ETC}_{I} \\
& \begin{aligned}
\frac{D}{n(1-\alpha) Q}\{ & S_{v}+m C_{0}+\frac{h_{v} n Q^{2}}{2} \\
& \times\left(\frac{2-n}{P}+\frac{(n-1)(1-\alpha)}{D}\right) \\
& +k \sum_{i=1}^{m} \int_{0}^{t_{i}} \alpha P\left(t_{i}-\tau\right) f(\tau) d \tau \\
& \left.+\sum_{i=1}^{m} \int_{0}^{t_{i}} r\left(t_{i}-\tau\right) f(\tau) d \tau+\sum_{i=1}^{m} C_{1} \bar{F}\left(t_{i}\right)\right\} \\
+ & h_{b}\left[\frac{Q(1-\alpha)}{2}+\frac{\alpha D Q}{x(1-\alpha)}\right] \\
+\frac{S_{b} D}{n(1-\alpha) Q} & +\frac{A D}{(1-\alpha) Q}+\frac{d D}{(1-\alpha)}+\frac{\eta}{\delta} \ln \frac{\alpha_{0}}{\alpha}
\end{aligned}
\end{aligned}
$$

where $\alpha_{0}$ is the original defect rate, a fixed value. $\alpha$ is the defect rate after investment; in this model, it is a decision variable; that is, we need to determine the optimal defect rate after quality improvement investment.

In order to obtain the optimal investment, taking the first derivative of $\mathrm{ETC}_{I}$ with respect to $\alpha$, we have

$$
\begin{aligned}
\frac{\partial \mathrm{ETC}_{I}}{\partial \alpha}= & \frac{D}{n(1-\alpha)^{2} Q}\left\{S_{v}+m C_{0}+\frac{h_{v} n Q^{2}}{2} \frac{2-n}{P}\right. \\
& +\sum_{i=1}^{m} \int_{0}^{t_{i}} r\left(t_{i}-\tau\right) f(\tau) d \tau \\
& \left.+\sum_{i=1}^{m} C_{1} \bar{F}\left(t_{i}\right)\right\} \\
& +\frac{D k}{n(1-\alpha)^{2} Q} \sum_{i=1}^{m} \int_{0}^{t_{i}} P\left(t_{i}-\tau\right) f(\tau) d \tau \\
& -\frac{h_{b} Q}{2}+\frac{h_{b} D Q}{x(1-\alpha)^{2}}+\frac{S_{b} D}{n(1-\alpha)^{2} Q} \\
& +\frac{A D}{(1-\alpha)^{2} Q}+\frac{d D}{(1-\alpha)^{2}}-\frac{\eta}{\delta \alpha} .
\end{aligned}
$$

Taking the second derivate of the total cost with respect to $Q, n, t_{i}$, it is clear that the $\mathrm{ETC}_{I}$ is still a convex function in $Q, n, t_{i}$ (since these operations are similar to those operations in the first model, we omit them).

To obtain the optimal solution, we adopt the iterative algorithm proposed by Ben-Daya and Hariga [31]. Using this algorithm, one can find the optimal solution in the following procedure.

Algorithm 2. Consider the following.

Step 1. Set $\mathrm{ETC}_{I}^{*}=\infty, n=1$.

Step 2. Set $\alpha=\alpha_{0}$ and compute $Q_{0}$ from (17).

Step 3. Compute $\alpha$ from (24) to zero. If $\alpha \geq \alpha_{0}$, set $\alpha=\alpha_{0}$. Update $t_{i}$ with $\alpha$ from (19).

Step 4. Compute $Q$ from (17) using $\alpha, t_{i}$. If $\left|Q-Q_{0}\right|=0$, compute ETC $\mathrm{E}_{I}$ and go to Step 5. Otherwise, set $Q=Q_{0}$ and go to Step 3.

Step 5. If $\mathrm{ETC}_{I}^{*} \geq \mathrm{ETC}_{I}$, set $\mathrm{ETC}_{I}^{*}=\mathrm{ETC}_{I}, \mathrm{Q}^{*}=\mathrm{Q}, \alpha^{*}=\alpha$, and $n=n+1$ and go to Step 2. Otherwise, $n^{*}=n-1$ and stop.

Note that $\partial \mathrm{ETC}_{I} / \partial \delta<0$ and $\partial \mathrm{ETC}_{I} / \partial \alpha_{0}>0$, which indicate that an increase in $\delta$ leads to a more reduction in the number of defective items per dollar increase in investment. 
TABLE 1: Optimal values of $n$ and $m$ for integrated vendor-buyer model.

\begin{tabular}{lccc}
\hline$n$ & $m$ & $Q^{*}(n)$ & $\operatorname{ETC}\left(n, Q^{*}(n)\right)$ \\
\hline 1 & 14 & 147.08 & 950.84 \\
2 & 22 & 109.14 & 829.69 \\
3 & 27 & 91.12 & 793.71 \\
4 & 32 & 79.73 & 781.86 \\
$5^{*}$ & $36^{*}$ & $71.57^{*}$ & $779.83^{*}$ \\
6 & 39 & 65.32 & 782.51 \\
7 & 42 & 60.32 & 787.67 \\
8 & 45 & 56.18 & 794.21 \\
9 & 47 & 52.69 & 801.51 \\
10 & 50 & 49.69 & 809.24
\end{tabular}

${ }^{*}$ The optimal solution.

\section{Numerical Examples and Managerial Implications}

For numerical study, we consider a single-vendor singlebuyer system; the following parameter values are set: production rate $P=320$, demand rate $D=100$, setup cost of vendor $S_{v}=300$, ordering cost of buyer $S_{b}=100$, inventory holding cost of vendor $h_{v}=2$, inventory holding cost of buyer $h_{b}=5$, transportation cost per shipment from vendor to buyer $A=25$, the screening rate for defective items in buyer $x=215$, per unit screening cost $d=0.5$, machine restoration cost per unit detection delay time for vendor $r=5$, process inspection cost and preventive maintenance cost $C_{0}=2$ and $C_{1}=15$, the per unit penalty cost for defective item $k=30$, and the original percentage of defective items without quality improvement investment $\alpha=0.05$. We also suppose that the time of the process shifts from in-control state to out-ofcontrol state follows uniform probability distribution; that is,

$$
f(x)= \begin{cases}\frac{1}{b}, & \text { if } 0<x<b \\ 0, & \text { otherwise. }\end{cases}
$$

3.1. Optimization Solution without Quality Improvement Investment. In this case, when $b=1$, we obtain the results as given in Table 1. Figure 4 shows that the total cost function ETC is convex in $n$. We solve this problem by using Algorithm 1. The optimal solution is $n^{*}=5, Q^{*}=71.5798$, $t_{i}^{*}=0.003$, and $m^{*}=36$, and the integrated average total cost is 779.8304. The optimal size of a production batch is 357.899 .

3.2. Optimization Solution with Quality Improvement Investment. Now, we consider the second one: integrated model with capital investment for reduction of defective items. In the first model, we additionally consider the parameter values $\alpha_{0}=0.05, \eta=2$, and $\delta=0.02$. Table 2 shows that when the original percentage of defective items is high, the effect of investment in quality improvement will be more obvious. This means that the total cost can be reduced more. This

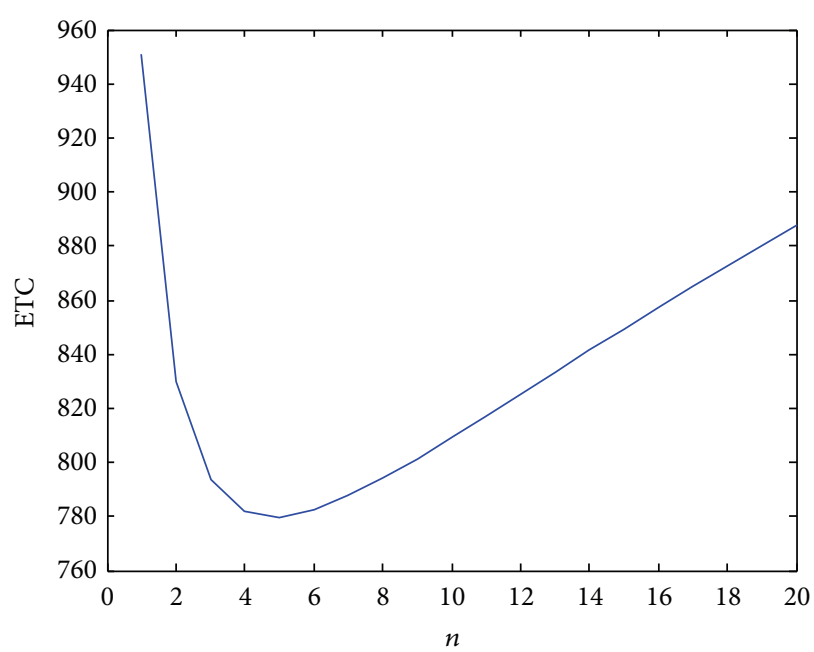

FIGURE 4: The behavior of ETC and $n$.

benefit will attract vendor to make an investment to reduce the defective items and make more profit.

From the numerical studies, it is shown that the optimal shipment size from the vendor to the buyer and the percentage of defective items decrease after quality investment. However, which one is better for the buyer?

Consider

$$
\begin{aligned}
\operatorname{ETC}_{B}(n, \alpha, Q)= & h_{b}\left[\frac{Q(1-\alpha)}{2}+\frac{\alpha D Q}{x(1-\alpha)}\right]+\frac{S_{b} D}{n(1-\alpha) Q} \\
& +\frac{A D}{(1-\alpha) Q}+\frac{d D}{(1-\alpha)} .
\end{aligned}
$$

Assume the difference between the total costs of buyer in the integrated model without and with quality improvement investment is $\Delta \mathrm{ETC}_{B}=\mathrm{ETC}_{1 B}(\alpha, Q)-\mathrm{ETC}_{B}(\alpha, Q)$.

When $\Delta \mathrm{ETC}_{B}(\alpha, \mathrm{Q})<0$, the investment is better for the buyer; otherwise there is no benefit for the buyer with investment.

Table 3 shows the comparison of annual cost for the buyer with and without investment. The numerical results show that the more the vendor invests in quality improvement, the more the benefit the buyer can obtain from the buyer's investment.

3.3. Sensitivity Analysis. In this subsection, we conduct sensitivity analysis for three important parameters: demand rate, production rate, and defect rate of product. We analyze how these three parameters impact the solution (in here, we take the first model as analysis basis).

(1) The Effect of Demand on Optimization Solution. We set the change range of demand rate from 100 to 200. Under this change range, the total cost increases from 779.8304 to 1313.5496 and the optimal shipment size increases from 71.5798 to 163.4827 . The optimal number of shipments per lot from the vendor to the buyer decreases from 5 to 3 ; the optimal number of machine inspections during each production 
TABLE 2: A comparison of the integrated model with and without investments.

\begin{tabular}{|c|c|c|c|c|c|c|c|}
\hline \multicolumn{3}{|c|}{ Model without investment } & \multicolumn{2}{|c|}{ Model with investment } & \multirow{2}{*}{$\alpha$} & \multicolumn{2}{|c|}{ Cost difference } \\
\hline$\alpha_{0}$ & $Q^{*}$ & ETC $^{*}$ & $Q^{*}$ & $\mathrm{ETC}_{I}^{*}$ & & $\Delta \mathrm{TC}$ & $\% \mathrm{TC}^{\mathrm{a}}$ \\
\hline 0.15 & 189.06 & 1466.58 & 178.62 & 1224.23 & 0.093 & 242.35 & 16.52 \\
\hline 0.20 & 237.14 & 1879.69 & 169.81 & 1201.90 & 0.081 & 677.78 & 36.05 \\
\hline 0.25 & 318.91 & 2354.98 & 162.86 & 1186.33 & 0.072 & 1168.65 & 49.62 \\
\hline 0.30 & 369.23 & 2871.18 & 157.33 & 1176.33 & 0.064 & 1694.85 & 59.02 \\
\hline 0.35 & 421.13 & 3476.24 & 146.23 & 1243.30 & 0.100 & 2232.93 & 64.23 \\
\hline
\end{tabular}

${ }^{\mathrm{a}}$ Note: $\% \mathrm{TC}=\left(\mathrm{ETC}^{*}-\mathrm{ETC}_{I}^{*}\right) / \mathrm{ETC}^{*}$.

TABLE 3: A comparison for the buyer with and without investments ${ }^{\mathrm{a}}$.

\begin{tabular}{|c|c|c|c|c|c|c|c|}
\hline \multicolumn{3}{|c|}{ Model without investment } & \multicolumn{2}{|c|}{ Model with investment } & \multirow{2}{*}{$\alpha$} & \multicolumn{2}{|c|}{ Cost difference } \\
\hline$\alpha_{0}$ & $Q^{*}$ & $\operatorname{ETC}_{B}^{*}(\alpha, Q)$ & $Q^{*}$ & $\operatorname{ETC}_{1 B}(\alpha, Q)$ & & $\Delta \mathrm{TC}$ & $\% \mathrm{ETC}_{B}^{*}$ \\
\hline 0.15 & 189.06 & 559.96 & 178.62 & 524.36 & 0.093 & 35.60 & 6.35 \\
\hline 0.20 & 237.14 & 693.11 & 169.81 & 501.79 & 0.081 & 191.31 & 27.60 \\
\hline 0.25 & 318.91 & 926.47 & 162.86 & 484.26 & 0.072 & 442.20 & 47.73 \\
\hline 0.30 & 369.23 & 1099.13 & 157.33 & 470.37 & 0.064 & 628.75 & 57.20 \\
\hline 0.35 & 421.13 & 1301.41 & 146.23 & 448.96 & 0.100 & 852.45 & 65.50 \\
\hline
\end{tabular}

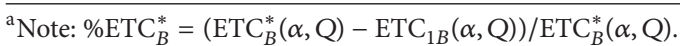

TABLE 4: Effect of demand rate on the optimal solution.

\begin{tabular}{lcccc}
\hline$D$ & $n^{*}$ & $m^{*}$ & $Q^{*}$ & ETC $^{*}$ \\
\hline 100 & 5 & 36 & 71.57 & 779.83 \\
120 & 4 & 37 & 93.93 & 889.78 \\
140 & 4 & 44 & 109.24 & 997.26 \\
160 & 4 & 50 & 126.00 & 1105.95 \\
180 & 3 & 44 & 148.07 & 1211.13 \\
200 & 3 & 49 & 163.48 & 1313.54 \\
\hline
\end{tabular}

TABLE 5: Effect of production rate on the optimal solution.

\begin{tabular}{lcccc}
\hline$P$ & $n^{*}$ & $m^{*}$ & $Q^{*}$ & ETC $^{*}$ \\
\hline 280 & 5 & 37 & 74.70 & 779.96 \\
300 & 5 & 36 & 72.99 & 779.78 \\
320 & 5 & 36 & 71.57 & 779.83 \\
340 & 5 & 35 & 70.39 & 780.00 \\
360 & 5 & 35 & 69.37 & 780.26 \\
\hline
\end{tabular}

run increases first and then decreases. The result is shown in Table 4. Summarily, demand increases will cause the increase in total cost and ordering quantity.

(2) The Effect of Production Rate on Optimal Solution. For analyzing the effect of production rate on optimal solution, we set the production rate increases from 280 to 360 . Table 5 shows the result.

From Table 5, we can see that, with the increase in production rate, the integrated total cost increases; at the same time, the optimal shipment size decreases, and the optimal number of machine inspections during each production run
TABLE 6: Effect of $\alpha$ on the optimal solution.

\begin{tabular}{lcccc}
\hline$\alpha$ & $n^{*}$ & $m^{*}$ & $Q^{*}$ & ETC $^{*}$ \\
\hline 0.01 & 6 & 5 & 46.55 & 573.46 \\
0.03 & 6 & 20 & 55.20 & 670.02 \\
0.05 & 5 & 36 & 71.57 & 779.83 \\
0.07 & 4 & 52 & 92.49 & 900.95 \\
0.10 & 3 & 76 & 126.91 & 1099.41 \\
\hline
\end{tabular}

decreases. But the optimal number of shipments per lot from the vendor to the buyer remains unchanged.

(3) The Effect of Defect Rate on Optimal Solution. We then analyze the effect of defect rate on optimal solution. From Table 6, one can see that, with an increase in the percentage of defective items, there is an increase in the number of inspections during each production run. This is intuitively true because when the vendor tries to reduce the defective items, more process inspections are needed during a production run. At the same time, the number of shipments per lot from the vendor to the buyer becomes less and the shipment size increases.

3.4. Managerial Implications. From the analytical model and numerical examples demonstration, we can conclude the following managerial implications for practitioners.

(1) Integration is a synchronization strategy in supply chain management; this paper demonstrates the benefit of integration optimization of production inventory of single vendor and single buyer in the supply chain. In practice, the vendor and the buyer should take joint action to optimize their operations. 
(2) Our study reveals that quality improvement investment in the vendor not only benefits the vendor, but also benefits the buyer. Investment can reduce total cost of the vendor and the buyer; furthermore, the more the investment of quality improvement of the vendor is, the higher the benefit the buyer gains. This implies that quality improvement has significant impact on the vendor and the buyer inventory optimization. Therefore, inventory manager of the vendor should pay attention to the quality issue of stocked items.

\section{Conclusions}

This paper investigates two integrated single-vendor singlebuyer inventory models, in which the vendor's production process is assumed to be imperfect, and JIT delivery policy is implemented to ship product from the vendor to the buyer. We analyze the two cases: one case is that the vendor has no quality improvement investment; the second case is that the vendor invests to improve quality.

We obtain the optimal number of shipments per lot from the vendor to the buyer and optimal machine inspections interval during each production run. We also calculate the optimal size of a production batch and the optimal shipment size from the vendor to the buyer.

The sensitivity of the key model-parameters, demand, production, and defect rate is examined. Analysis reveals that an increase in demand rate causes increase in the number of process inspections and decrease in the production lot size. It is also shown that an increase in the production rate causes an increase in shipment size but a decrease in the number of machine inspections, while the production lot size does not change. Further, we consider that the vendor carries out a capital investment for reduction of defective items. After investment, the percentage of defective items reduces. The investment can cause both the optimal shipment size and the integrated total cost decrease. Furthermore, the numerical results show that when the original percentage of defective items is high, the effect of investment becomes more obvious.

The future research of this paper can follow these directions. First, we can incorporate the machine reliability into the models and analyze how it affects the integrated decision. Second, the models can be extended to consider setup cost reduction in production and variable shipment size. Third, the models can also be extended to consider multiple buyers.

\section{Conflict of Interests}

The authors declare that there is no conflict of interests regarding the publication of this paper.

\section{Acknowledgment}

This research was supported by the National Natural Science Foundation of China, under Grant no. 71372154.

\section{References}

[1] M. J. Rosenblatt and H. L. Lee, "Economic production cycles with imperfect production processes," IIE Transactions, vol. 18, no. 1, pp. 48-55, 1986.

[2] M. K. Salameh and M. Y. Jaber, "Economic production quantity model for items with imperfect quality," International Journal of Production Economics, vol. 64, no. 1, pp. 59-64, 2000.

[3] H. M. Wee, J. Yu, and M. C. Chen, "Optimal inventory model for items with imperfect quality and shortage backordering," Omega, vol. 35, no. 1, pp. 7-11, 2007.

[4] L. E. Cárdenas-Barrón, "Economic production quantity with rework process at a single-stage manufacturing system with planned backorders," Computers and Industrial Engineering, vol. 57, no. 3, pp. 1105-1113, 2009.

[5] K.-J. Chung, "The economic production quantity with rework process in supply chain management," Computers \& Mathematics with Applications, vol. 62, no. 6, pp. 2547-2550, 2011.

[6] H.-C. Chang and C.-H. Ho, "Exact closed-form solutions for "optimal inventory model for items with imperfect quality and shortage backordering"," Omega, vol. 38, no. 3-4, pp. 233-237, 2010.

[7] J.-T. Hsu and L.-F. Hsu, "An EOQ model with imperfect quality items, inspection errors, shortage backordering, and sales returns," International Journal of Production Economics, vol. 143, no. 1, pp. 162-170, 2013.

[8] M. Khouja and A. Mehrez, "An economic production lot size model with imperfect quality and variable production rate," Journal of the Operational Research Society, vol. 45, no. 12, pp. 1405-1417, 1994.

[9] S. S. Sana, "An economic production lot size model in an imperfect production system," European Journal of Operational Research, vol. 201, no. 1, pp. 158-170, 2010.

[10] C.-K. Huang, "An integrated vendor-buyer cooperative inventory model for items with imperfect quality," Production Planning and Control, vol. 13, no. 4, pp. 355-361, 2002.

[11] S. K. Goyal, C.-K. Huang, and K.-C. Chen, "A simple integrated production policy of an imperfect item for vendor and buyer," Production Planning and Control, vol. 14, no. 7, pp. 596-602, 2003.

[12] C.-K. Huang, "An optimal policy for a single-vendor singlebuyer integrated production-inventory problem with process unreliability consideration," International Journal of Production Economics, vol. 91, no. 1, pp. 91-98, 2004.

[13] L.-Y. Ouyang, K.-S. Wu, and C.-H. Ho, "Analysis of optimal vendor-buyer integrated inventory policy involving defective items," International Journal of Advanced Manufacturing Technology, vol. 29, no. 11-12, pp. 1232-1245, 2006.

[14] J.-T. Hsu and L.-F. Hsu, "An integrated vendor-buyer inventory model with imperfect items and planned back orders," International Journal of Advanced Manufacturing Technology, vol. 68, no. 9-12, pp. 2121-2132, 2013.

[15] J.-T. Hsu and L.-F. Hsu, "An integrated vendor-buyer cooperative inventory model in an imperfect production process with shortage backordering," International Journal of Advanced Manufacturing Technology, vol. 65, no. 1-4, pp. 493-505, 2013.

[16] L. Marek, "On the problem of optimization of a quality inspection process structure," International Journal of Production Research, vol. 21, no. 3, pp. 369-381, 1983.

[17] H. L. Lee and M. J. Rosenblatt, "Simultaneous determination of production cycle and inspection schedules in a production system," Management Science, vol. 33, no. 9, pp. 1125-1136, 1987. 
[18] B. C. Giri and T. Dohi, "Inspection scheduling for imperfect production processes under free repair warranty contract," European Journal of Operational Research, vol. 183, no. 1, pp. 238-252, 2007.

[19] J. T. Hsu and L. F. Hsu, "An integrated single-vendor singlebuyer production-inventory model for items with imperfect quality and inspection errors," International Journal of Industrial Engineering Computations, vol. 3, no. 5, pp. 703-720, 2012.

[20] M. Khan, M. Y. Jaber, and M. Bonney, "An economic order quantity (EOQ) for items with imperfect quality and inspection errors," International Journal of Production Economics, vol. 133, no. 1, pp. 113-118, 2011.

[21] J.-T. Hsu and L.-F. Hsu, "A note on "optimal inventory model for items with imperfect quality and shortage backordering"," International Journal of Industrial Engineering Computations, vol. 3, no. 5, pp. 939-948, 2012.

[22] H.-H. Lee, "A cost/benefit model for investments in inventory and preventive maintenance in an imperfect production system," Computers and Industrial Engineering, vol. 48, no. 1, pp. 55-68, 2005.

[23] S. H. Yoo, D. Kim, and M.-S. Park, "Inventory models for imperfect production and inspection processes with various inspection options under one-time and continuous improvement investment," Computers \& Operations Research, vol. 39, no. 9, pp. 2001-2015, 2012.

[24] T. Avinadav and Y. Perlman, "Economic design of offline inspections for a batch production process," International Journal of Production Research, vol. 51, no. 11, pp. 3372-3384, 2013.

[25] C.-J. Chung, "Investigating imperfect process and demand effects on inspection scheduling and supply chain replenishment policy," Computers and Industrial Engineering, vol. 64, no. 1, pp. 31-44, 2013.

[26] M. Khan, M. Y. Jaber, and A.-R. Ahmad, "An integrated supply chain model with errors in quality inspection and learning in production," Omega, vol. 42, no. 1, pp. 16-24, 2014.

[27] E. L. Porteus, "Optimal lot sizing, process quality improvement and setup cost reduction," Operations Research, vol. 34, no. 1, pp. 137-144, 1986.

[28] J.-D. Hong, "Optimal production cycles, procurement schedules, and joint investment in an imperfect production system," European Journal of Operational Research, vol. 100, no. 3, pp. 413-428, 1997.

[29] K.-L. Hou, "An EPQ model with setup cost and process quality as functions of capital expenditure," Applied Mathematical Modelling, vol. 31, no. 1, pp. 10-17, 2007.

[30] S. H. Yoo, D. Kim, and M.-S. Park, "Lot sizing and quality investment with quality cost analyses for imperfect production and inspection processes with commercial return," International Journal of Production Economics, vol. 140, no. 2, pp. 922-933, 2012.

[31] M. Ben-Daya and M. Hariga, "Integrated single vendor single buyer model with stochastic demand and variable lead time," International Journal of Production Economics, vol. 92, no. 1, pp. 75-80, 2004. 


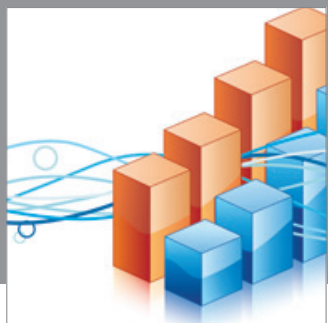

Advances in

Operations Research

mansans

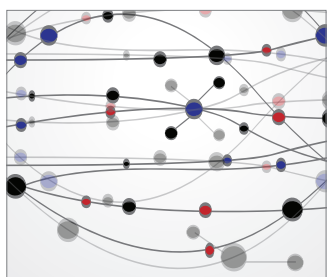

The Scientific World Journal
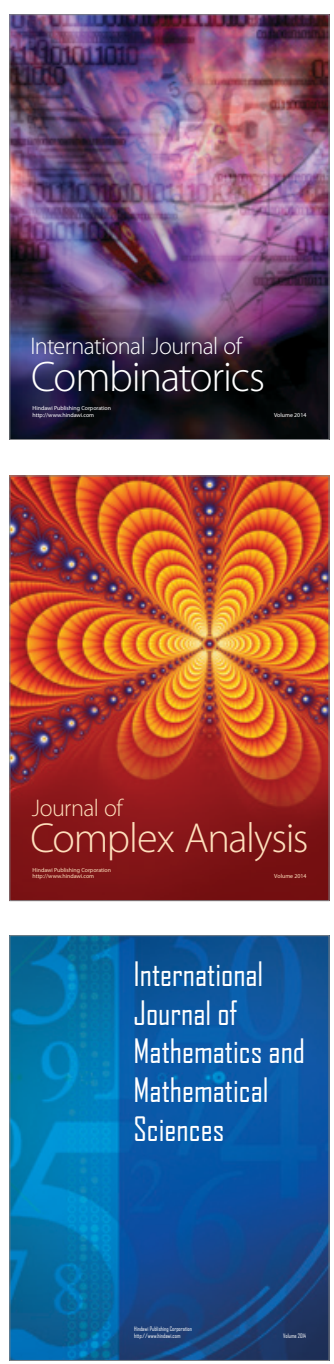
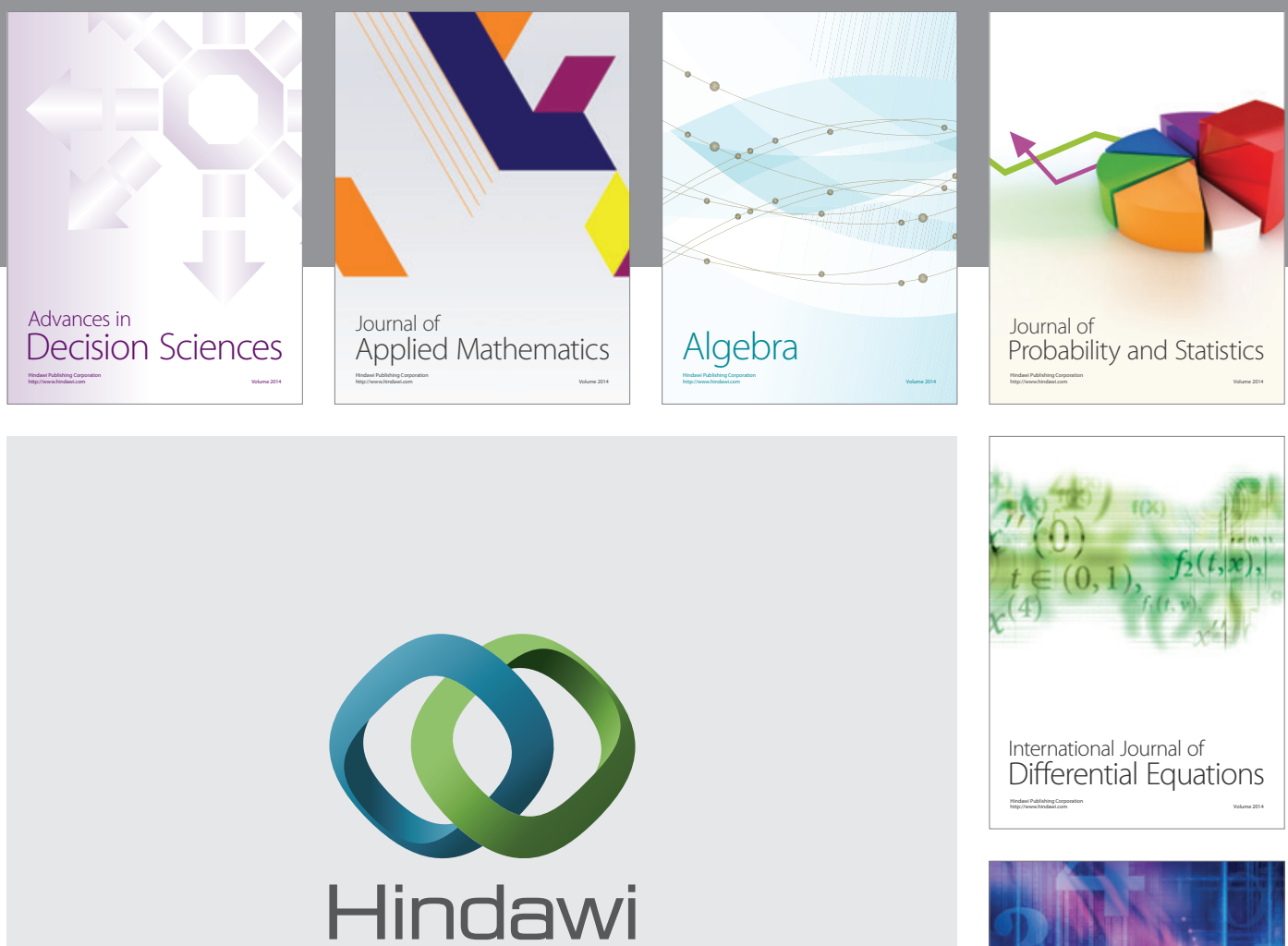

Submit your manuscripts at http://www.hindawi.com
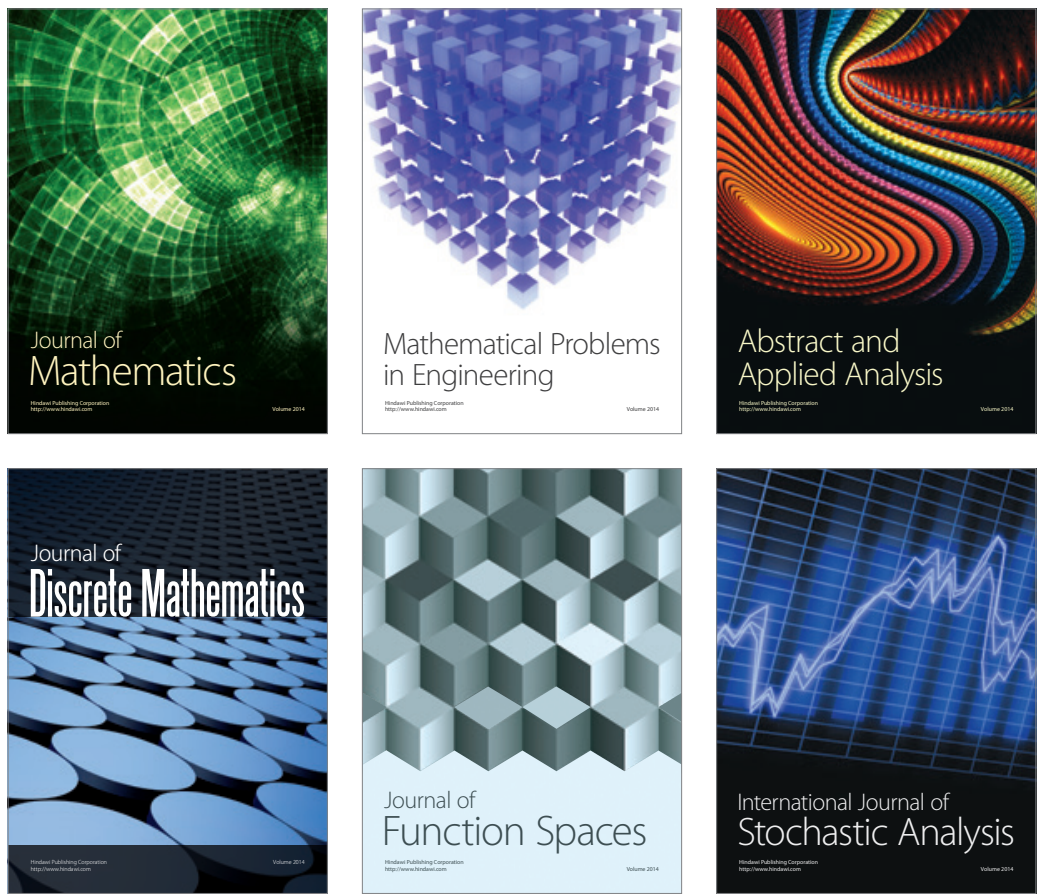

Journal of

Function Spaces

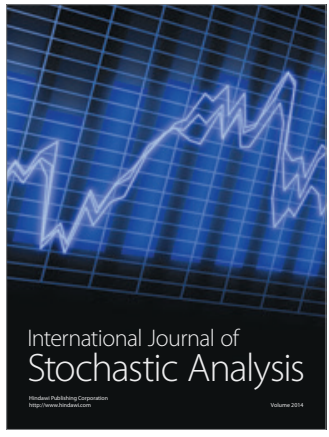

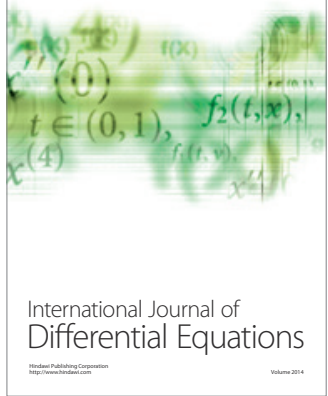
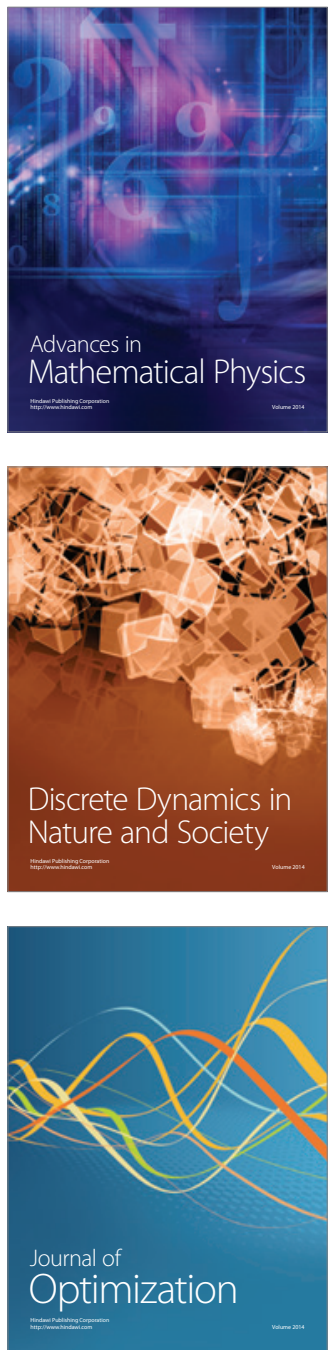